\title{
Giant adenofibroma of the breast
}

INSERM

\section{Source}

INSERM. (1999). Orphanet: an online rare disease and orphan drug data base. Giant adenofibroma of the breast. ORPHA:180267

Giant adenofibroma of the breast is a rare, benign, fibroepithelial tumor which usually manifests as a unilateral, painless, firm, mobile, slow-growing mass in the breast that measures more than $5 \mathrm{~cm}$. It can be associated with significant asymmetry and/or deformity of the breast and hormonal changes (e.g. puberty, pregnancy, oral contraceptives) can lead to its marked enlargement. 